\title{
INTEGRATED HYDRAULIC MODEL AND GENETIC ALGORITHM OPTIMIZATION FOR INFORMED ANALYSIS OF A REAL WATER SYSTEM
}

\author{
Chris Clark \\ Director of Public Utility Department \\ City of Sidney, OH, USA. \\ Email: cclark@sidneyoh.com \\ Zheng Yi Wu \\ Haestad Method Solution Center, Bentley Systems, Incorporated \\ 27 Siemon Co. Dr., Suite 200W \\ Watertown, CT06795, USA \\ Email: zheng.wu@bentley.com
}

\begin{abstract}
A hydraulic network model was constructed for the City of Sidney, Ohio water distribution system. It consists of 104 miles of water mains, some of which are well over a hundred year old and serve the original part of the system. The City intends to use the model for available fire flow analysis and a variety of many other applications. It is essential that the hydraulic model be able to accurately simulate the real system conditions. Model calibration is the critical step to achieve this goal. To calibrate the model, Sidney's Public Utility Department collected the pressure data at twenty locations, along with the boundary conditions of the observed tank levels and pump operating status. The calibration proceeds by applying a well-integrated hydraulic simulation and genetic algorithm optimization modeling platform in two phases including the systemic demand calibration to establish an extended period flow balance model and hydraulic grade calibration under multiple loading conditions. The model calibration performed for the Sidney water distribution model improves the confidence in the modeling results. It assists the engineers to better understand the insight into the system hydraulics and enhances modeling quality for evaluating the available fire flow and system improvement design. This paper illustrates the critical steps of the calibration process and the applications of the calibrated model for the City of Sidney.
\end{abstract}

\section{Key Word}

Water system, network hydraulic model, genetic algorithm, optimization, fire flow analysis, system design

\section{INTRODUCTION}

\section{Service Area and Distribution Mains}

The service area of the Sidney water distribution system is comprised of the developed areas within the City limits. The service area is generally hilly with ground elevations ranging from a low of approximately 903 feet above mean sea level near the Great Miami River, to a height of approximately 1061 feet near Russell Road and Fourth Avenue.

The existing distribution network consists of water lines ranging in size from 4-inches to 30-inches in diameter. Cast iron mains, some of which are well over a hundred years old, service the older parts of the City which is mostly the downtown area. Most of the newer sections of the City are ductile iron pipe due 
simply because of the excellent track record of this product. The City's Engineering Standards require the use of Class 53 cement line ductile iron pipe. The City has no PVC water mains in the system.

\section{System Storage}

Sidney has two above ground water storage tanks and one underground storage tank to maintain system pressure and to provide water for fighting fires. The Campbell Road Tank is a one million gallon (MG) elevated tank located on Campbell Road, east of Stolle Avenue. The Fourth Avenue Tank is a 2.0 MG elevated tank located on Fourth Avenue, south of Russell Road. The overflow elevation of each tank is 1161.0 feet above mean sea level. The underground storage tank is a 2.0 MG clearwell at the Water Plant which provides underground storage to the east end of the City.

\section{High Service Pumps}

Water is supplied from the Water Treatment Plant to the City via four (4) high service pumps with the rated capacity of 2, 3, 4 and $7 \mathrm{mgd}$. The Water Treatment Plant staff operates the high service pumps based on water level in the elevated tanks, system pressure, and past experience.

\section{WATER USAGES}

Water use in a community varies with the seasons of the year, the days of the week, and the hours of the day. Besides normal variations, water line breaks and fire emergencies can impose additional high demands on the system at any time. A community's water works must be designed to meet all averageday, maximum-day, and maximum-hour demands while maintaining reserve for fire protection.

In most Midwestern communities, maximum-day use is 1.2 to 3 times as large as the use on the averageday. The demand during the maximum-hour typically is 1.2 to 1.7 times as great as the maximum-day rate. Fire flow evaluations are usually superimposed on maximum-day conditions to ensure the system has adequate safety reserve.

Elevated storage facilities generally are designed to augment the distribution of water during maximumhour and maximum-day plus fire flow conditions. Tank storage should be capable of being replenished before water demand begins to increase the following day.

\section{Present-Day Demands}

Sidney's present average-day demands, maximum-day demands and the ratio of maximum-day to average-day water use for the years from 1988 to 1999 are listed in Table 1. The data listed is the volume of water pumped into the distribution system from the Water Treatment Plant.

For this study, present average-day demand was taken to be $3.1 \mathrm{mgd}$ and both present and future maximum-day to average-day ratios was decided to be 1.5 . The present and future maximum-hour to maximum-day ratios also was assumed to be 1.5 .

Large water users are in range of 1000 gpd to 506,800 gpd in average-day usage and 1,400 gpd to 621,200 gpd at maximum-day usage.

\section{Per Capita Water Usage}


Of the 3,100,000 gpd present average-day water usage, 1,240,000 gpd, or 40\%, is attributable to large users and 1,860,000 gpd, or $60 \%$ is attributable to the residential, commercial, institutional, and small industrial users.

Table 1 Water usage for City of Sidney water system

\begin{tabular}{c|c|c|c}
\hline \hline Year & $\begin{array}{c}\text { Average-day } \\
\text { (mgd) }\end{array}$ & Maximum-day (mgd) & $\begin{array}{c}\text { Ratio of maximum-day to } \\
\text { Average-day }\end{array}$ \\
\hline 1988 & 2.85 & 4.23 & 1.49 \\
1989 & 2.89 & 3.73 & 1.29 \\
1990 & 2.95 & 3.72 & 1.26 \\
1991 & 3.00 & 4.03 & 1.34 \\
1992 & 2.84 & 3.80 & 1.34 \\
1993 & 2.87 & 3.94 & 1.37 \\
1994 & 2.83 & 3.56 & 1.26 \\
1995 & 3.21 & 4.55 & 1.42 \\
1996 & 3.14 & 4.63 & 1.47 \\
1997 & 3.00 & 4.08 & 1.36 \\
1998 & 3.10 & 3.98 & 1.28 \\
\hline \hline
\end{tabular}

Per capita water use was calculated based on Sidney's 1990 water use, population, and population density. From Table 1, average 1990 water use was 2,950,000 gpd. Of this, industrial water use was about $40 \%$, or $1,180,000 \mathrm{gpd} ; 60 \%$ of the water use, or $1,770,000 \mathrm{gpd}$, was believed to be attributable to residential, commercial, institutional, and small industrial users. According to Sidney's 1997 Comprehensive Plan, Sidney's 1990 population was 18,710, and the 1990 population density was 2.66 people per household ( $\mathrm{pph}$ ). Total per capita water usage and the per capita water use without large users were calculated as follows:

- Total water usage per capita of 2,950,000 gpd / 18,710 people $=158$ gpd per capita (gpcd)

- Water usage per capita without large users of 1,770,000 gpd / 18,710 people $=95 \mathrm{gpcd}$

Typical residential-only average per capita usage is 65 gpcd. Sidney's combined residential, commercial, institutional, and small industrial per capita usage is 95 gpcd; commercial, institutional, and small industrial average usage, on a per capita basis is, therefore, estimated to be 30 gpcd.

\section{Typical Maximum Fire Flows}

The ability of a water distribution system to meet variations in water demand caused by fire fighting is assessed by comparing the model-realized fire flows at 20 psi residual pressure to typical fire-fighting flows. Needed fire flow rates normally are estimated based on population density and vary between residential, commercial, institutional, and industrial areas. Table 2 includes the targeted fire flow rates used in Sidney's distribution system analysis and all new development is required to attempt to achieve the respective targeted fire flow.

\section{HIGH SYSTEM PRESSURES}


The maximum pressure identified in the computer model of the existing system was 102.3 psi at the east end of Poplar Street near the Great Miami River. Two general areas exhibit pressures in excess of 90 psi during present day demands are: the area west of the Water Treatment Plant near the Great Miami River and the area near the south end of Brooklyn Avenue and the west end of Gearhart Road. Some pressures in these areas are higher than the Ten States Standards' recommended maximum pressure of 100 psi. The City currently minimizes the high pressures by limiting the Water Treatment Plant discharge pressure to 70 psi. This is done by monitoring the water levels in the elevated tanks and operating the appropriate high service pumps at the Water Treatment Plant.

Table 2 Targeted fire flow rates

\begin{tabular}{l|l|l}
\hline \hline \multicolumn{1}{c|}{ Descriptions } & Designations & Fire Flows (gpm) \\
\hline Residential Areas & RES & 1,000 to 1,500 \\
Commercial Areas & COM & 2,500 to 3,000 \\
Institutional Areas & INST & 2,500 to 3,000 \\
Industrial Areas & IND & 4,000 to 4,500 \\
\hline \hline
\end{tabular}

\section{LOW SYSTEM PRESSURES}

Two general areas exhibit pressures lower than 35 - 45 psi during present day demands: the area north and south of Hoewisher Road between St. Marys Avenue and Thompson-Schiff Road; and the area bounded by Vandemark Road, Fourth Avenue, Russell Road, and State Route 47. Although these pressures are typically higher than the Recommended Standards for Water Works' (Ten States Standards) recommend minimum pressure of 35 psi, the City has received numerous pressure complaints from residents in the Hoewisher Road area.

\section{WATER MODELING}

There are numerous factors that influenced the City's decision to develop a water model of its distribution system. Some of those factors are:

1. Rapid industrial and residential growth;

2. High pressure in the downtown area;

3. Low pressure in the north end of the City;

4. $\quad$ High demand on the west end of the City (heavy industrial);

5. Inadequate Fire Flows in certain areas.

In order to address the various problems, the City of Sidney developed a water model of the distribution system. Prior to 2000, any water distribution design for new development was evaluated by Jones \& Henry Engineers, Toledo, Ohio using Haested's WaterCAD. The water model that was developed by $\mathrm{J} \& \mathrm{H}$ was skeletonized and only contained large transmission mains. The water model was incomplete as a development and evaluation tool. In 2000, the City obtained the Haested WaterCAD program and completed the model update. Calibration of the model was performed by City staff with the assistance and an on-site visit of the second author from Haested Methods.

\section{MODEL CALIBRATION}

The model calibration has been undertaken in two steps including flow balance calibration and hydraulic grade calibration by using Darwin Calibrator, a genetic algorithm based optimization model calibration tool (Wu et al. 2002; Wu et al. 2004) that is built into WaterCAD (Haestad 2002) and WaterGEMS (Bentley 2006). 


\section{Flow Balance Calibration}

The initial comparison of the simulated and the observed tank levels for the tank at Campbell Road indicated the significant discrepancy as uncovered in Figure 1. The model predicted that the tank level at Campbell Road remained full, but the observed tank level did show the variation over 24 hours. It was also noticed that the total system demand simulated over 24 hours was 1.2 million gallons instead of about 4.0 million gallons for a typical summer day as recorded at the pump station. The mismatched tank levels and system demand clearly pointed out that the extended period simulation (EPS) model is not balanced. It needs to be calibrated to match the tank level and system demand.

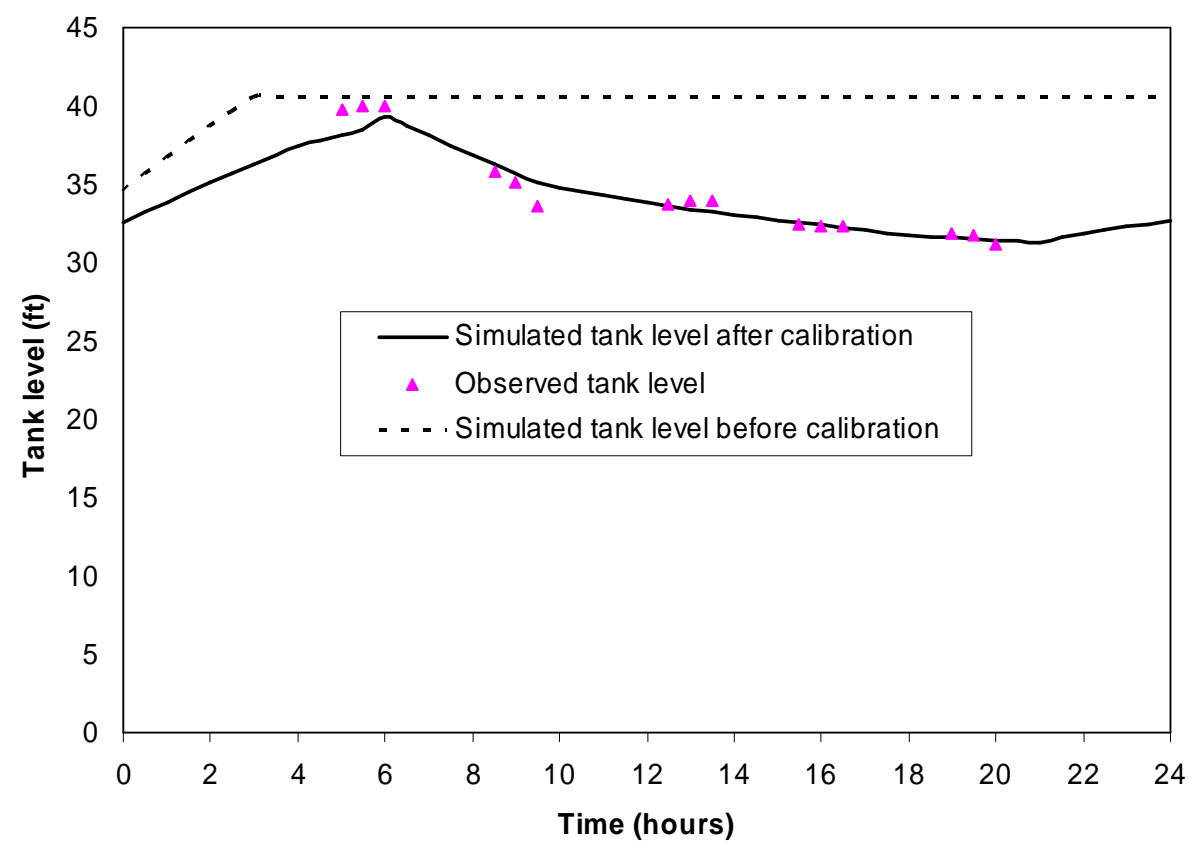

Figure 1 Comparison of tank levels between the observed and calibrated values at tank at Campbell Road for flow balance.

Since the system is supplied by pumping the water from the treatment plant. The pump controls are the key to be accurately modeled as they are operated in the real system. Three pumps PMP-2mgd, PMP$3 \mathrm{mgd}$ and PMP-4mgd are controlled by tank level at Campbell Road. The operating status (ON and OFF) is set by the operator using a SCADA interface. It is triggered by the tank level, but the pump combination is different from the day to the night to fill the tank and maintain the tank level as required. Therefore, operating status (ON/OFF) for each pump at a given time step is the key parameter to be calibrated to match the tank levels while the system demand is calibrated by using a demand multiplier for the entire system. The task for the extended period flow balance calibration is to minimize the difference between the simulated and observed tank levels, and also the difference between the model simulated and the filed observed system demand. Using the calibration algorithmic framework, this calibration task is conducted by choosing the link status for the pumps and one demand multiplier for all junctions as one demand group. Calibration of pump control and system demand enables a good match between the model predicted and the observed tank levels, as illustrated in Figure 1. A system wide demand multiplier of 3.2 was obtained to well match the system demand of 3.84 million gallon for a typical summer day. It has significantly improved the EPS modeling accuracy. 


\section{Hydraulic Grade Calibration}

Initial effort of applying the optimal calibration tool was made to organize and input field data. Due to the variation of system demand and operation conditions (tank level and pump status), each data set must contain a set of the field observed pressures and corresponding boundary conditions at the same instance of time. Thus five data sets have been created to keep the consistency between the measured pressures and operation scenarios.

To better reflect the system condition for each calibration dataset, junction demand needs to be adjusted along with pipe roughness. Twenty (20) pipe roughness groups have been carefully defined so that each group comprises the pipes that are hydraulically sensitive to at least one observed pressure point. The pipes within one roughness group are adjusted by multiplying the original roughness with the same multiplier. Alternatively, a user can choose to set the roughness values instead of applying roughness multipliers. In that case, the integrated calibration tool will adjust all the pipes in the group to the same roughness value. Junctions have been grouped by demand type. Four junction groups have been established for the demand types including Industrial, Commercial, Residential and Other (for all the unknown type of demand).

The last step of setting up the model calibration is to select calibration criteria. Three goodness-of-fit criteria or fitness types are available for quantifying the distance between the model predicted and the field observed values. Minimize absolute difference is chosen for conducting the calibration. Calibration runs are then undertaken for analyzing the model behavior and sensitivity. Each run is consistently persisted so that modelers can browse, export and analyze the results at their convenience.

A number of calibration runs have been conducted for all five data sets. Each run has improved the goodness-of-fit between the observed pressures and the simulated pressures. Calibration results are presented in different sections including calibrated roughness, demand and pressure comparison, as shown in Figure 2 (calibration run for hour 8:30 AM data).

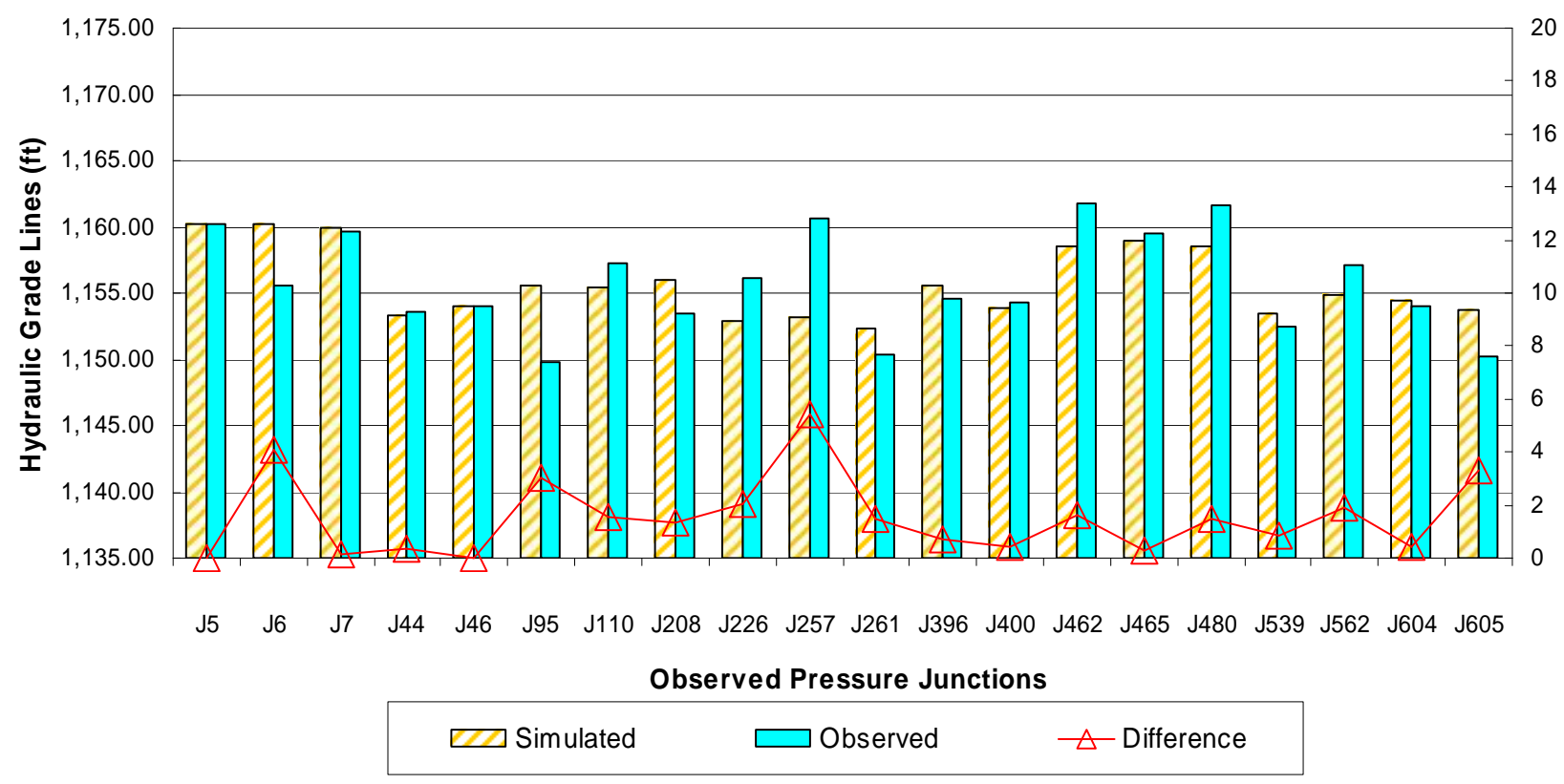

Figure 2 Comparison between the field observed and model simulated hydraulic grade lines at hour $12: 30 \mathrm{PM}$ 


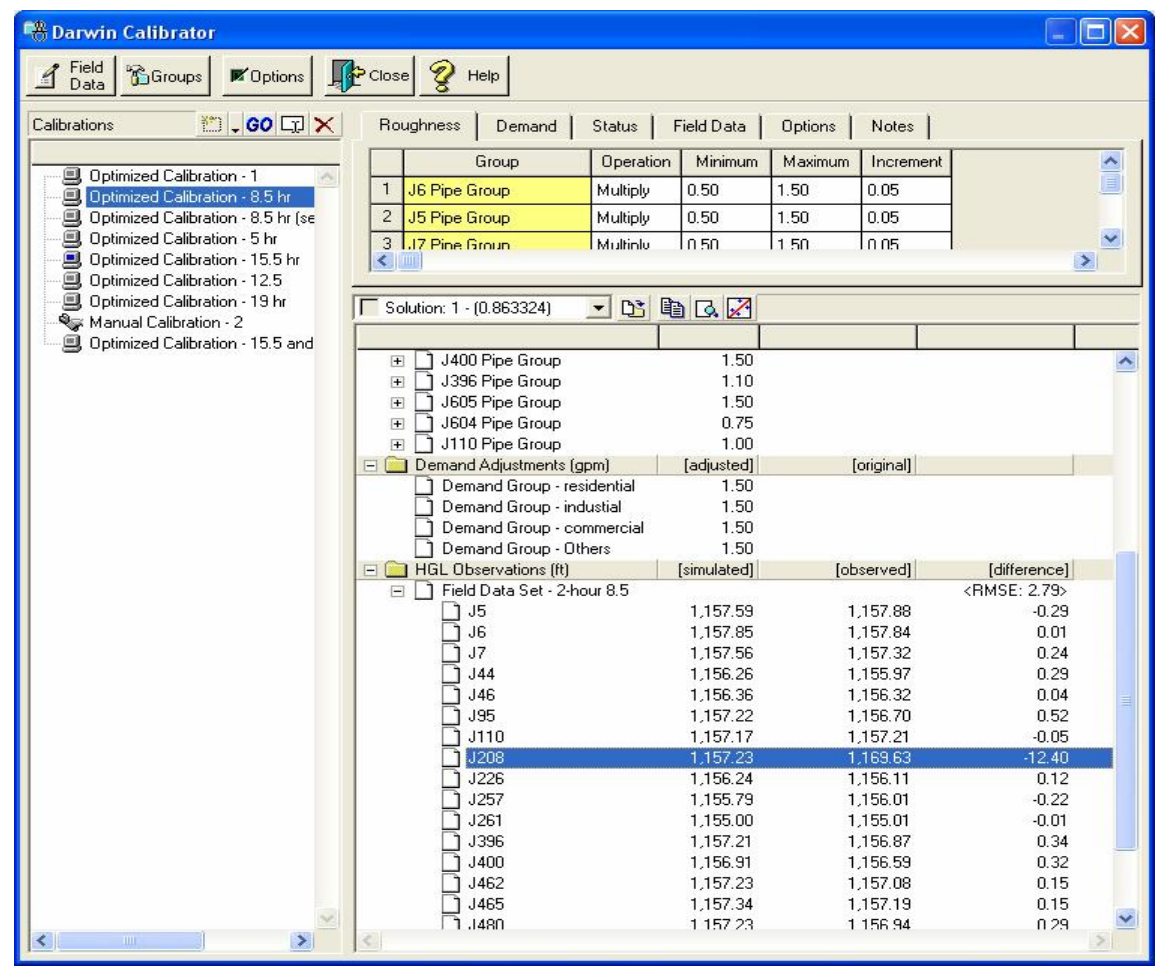

Figure 3 Results of hydraulic calibration run for 8:30 AM dataset

Of all five data sets, the calibration run for field data at hour 8:30 AM produced the best-fit solution of the minimum discrepancy between the observed and simulated pressures. It results in less than $1 \%$ difference between the observed and the simulated pressures for most of data points except at junction J208, as highlighted as Figure 3. It clearly indicates that the measurement at J208 appears to be problematic at hour 8:30 AM. The calibration of the other four data sets also demonstrate the good agreement between the field observed and model simulated for most of the data points. As illustrated in Figure 2, the difference is within 5\% pressure difference for majority of data points, the maximum pressure head difference is about $5 \mathrm{ft}$. In addition to optimizing the model parameters, GA-based calibration method also identifies the possible abnormal measurements from the field, including junction J257 at 12:30 PM, J465 at 3:30 PM and J562 at 7:00 PM. These data points clearly exemplify the significant difference than the most of measurements.

Calibration analysis performed for the Sidney water distribution model improves the confidence in the modeling results. It has also been continuously refined and calibrated to maintain and improve the modeling accuracy for the ongoing system changes.

\section{INFORMED ANALYSIS}

The City utilizes the calibrated model for a variety of applications including:

1. Modeling the water system for new City subdivisions;

2. Reporting annexation assessment;

3. Modeling for new or expanding industrial users

4. Developing fire flows for a new Hydrant Tagging System;

5. Providing pressure fire flow data to developers, engineers, architects and plumbers. 
The City's model is currently being used by CH2MHill Engineering, Columbus, Ohio for the development of pressure zones within the City which is crucial for continued growth. The following are just two examples of the model applications.

\section{Example 1: Kuther Rd Water Main Extension}

\section{Existing Water Mains}

Currently, there is a 16" water main on Millcreek Rd that stops in front of the Stephens Subdivision. This is approximately 1,200 ft from the Kuther Rd/Millcreek Rd intersection. Additionally, there is a 16" water main on Kuther Rd that ends on the northwest corner of S.E. Johnson's property (east side). The water pressure and fire flow availability for these two mains are as follows:

- Millcreek Water Main at Dead End: Static Pressure: 57 psi, available Fire Flow @ 20 psi Residual: 3,100 gal/min;

- Kuther Rd Water Main at Dead End: Static Pressure: 60 psi, available Fire Flow @ 20 psi Residual: $2,300 \mathrm{gal} / \mathrm{min}$.

Available Water Service

There are two water mains available for the proposed development. In order to determine which main is best for connection, the Utilities Department had to run the water model for the proposed development. The model was based on a road elevation at the intersection of Kuther Rd and Millcreek at $1009 \mathrm{ft}$. and a water demand of $400 \mathrm{gal} / \mathrm{min}$ from the proposed development.

The model was run on three scenarios. Scenario \#1 was based on extending the 16 " water main from its present location on Kuther Rd in front of S.E. Johnson property to the intersection of Millcreek \& Kuther. Scenario \#2 was based on extending the 16" water main from its present location on Millcreek Rd to the intersection of Kuther and Millcreek Rd. Scenario \#3 was based on both water mains being looped or connected together at Millcreek \& Kuther Rd. The following are the results of the model.

- Scenario \#1 - Connection to Kuther, Static Pressure: 62 psi, available Fire Flow @ 20 psi Residual: $1,800 \mathrm{gal} / \mathrm{min}$;

- Scenario \#2 - Connection to Millcreek: Static Pressure: 62 psi, available Fire Flow @ 20 psi Residual: $3,200 \mathrm{gal} / \mathrm{min}$;

- Scenario \#3 - Connection to Looped Water Mains: Static Pressure: 62 psi, available Fire Flow @ 20 psi Residual: 4,100 gal/min.

As an understanding of fire flow, the City Fire Department's target (desired) for fire flows for industrial development is 5,000 gal/min or higher. As you can see, neither Scenario \#1 nor Scenario \#2 can meet the fire flow criteria. The only way to improve the fire flows is to loop the two water mains together. We still don't achieve the 5,000 gpm standard but it is the best improvement that can be expected. As stated earlier, the model was based on an estimated demand of $400 \mathrm{gal} / \mathrm{min}$ from the development. If the demand is greater than $400 \mathrm{gpm}$ then it only reinforces the need for the water loop.

\section{Example 2: City Fire Flow Analysis and Tagging System}

One of the objectives of any municipal Fire Department is to have extensive knowledge of the distribution system. Without the development of the water model, Fire Department personnel would manually perform fire flow tests on several hydrants in the City per year. This information was entered into a program called Fire House. This information was helpful to the Fire Department in knowing the available fire flows in an area and was helpful in giving this information to Sprinkler Contractors. 
In 2001, the Fire Department initiated discussions with the Utilities Department on initiating a Hydrant Tagging System. It was their intent to physically assign a number to each hydrant in the City. During a fire, they could access the Fire House program and could advise the firemen of the hydrant number as well as the physical location.

During the development of the Hydrant Tagging System, it was suggested that the Hydrant Tags be color coded along with their assigned numbers to the appropriate available fire flow. There are over 1,400 hydrants in the City and the Fire Department did not have the necessary manpower to physically flow the hydrants for the data that they needed. The Utilities Department turned to the water model.

The water model, once it was fully calibrated, has the capability of calculating the available fire flows for each node in the system. While the node does not represent a hydrant, it can be used as a reference point to the closest available hydrant. With the ability to model the fire flows, the Fire Department wanted to utilize the National Fire Protection Association's (NFPA) Standards for the color coding.

\section{RATING SYSTEM USING NFPA STANDARDS \\ BLUE \\ GREEN \\ ORANGE \\ RED \\ $>1,500$ Gallons/Min \\ $1,000-1,500$ Gallons/Min \\ $500-1,000$ Gallons/Min \\ $<500$ Gallons/Min}

The Utilities Department initiated a run/scenario on the water model using normal operating conditions. Such as; the towers being at their nominal levels and the Water Plant turning on their largest high service pump when notified of the fire as is standard procedures. The nodes were calculated for fire flow with the residual pressure set at 20 psi.

Next, City staff assigned each hydrant in the Hydrant Map to a node in the water model. We were then able to provide modeled fire flows for each hydrant in the City. The pictures in Figure 6 show the Hydrant Tagging System.

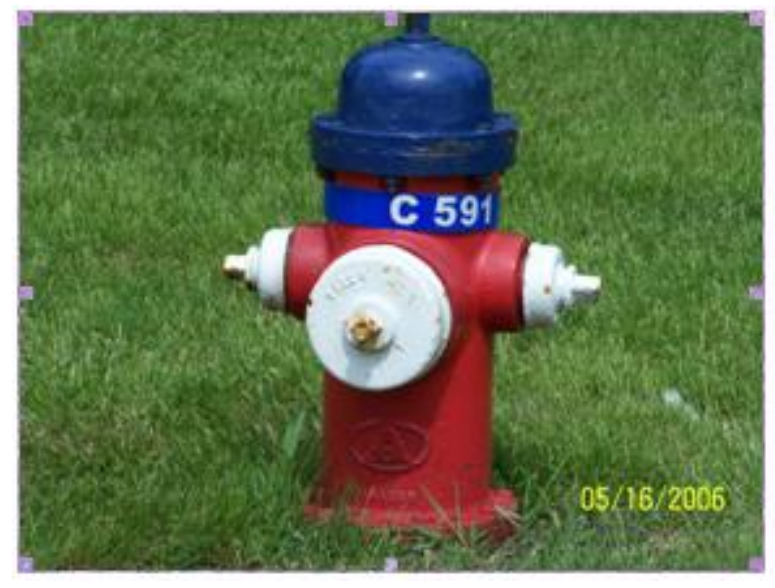

Figure 4 (a) Blue hydrant: > 1,500 gpm

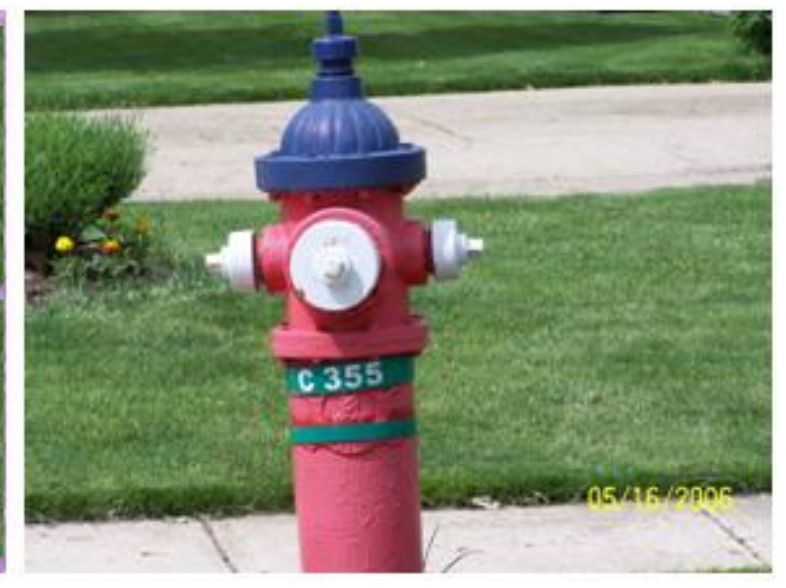

(b) Green hydrant: 1,000-1500 gpm

As you can see, not only does each hydrant have an identifying number, but each is color coded to their modeled fire flow. This is extremely beneficial to the Fire Department in that when a fire occurs, if the firemen see two hydrants available and one has a green band while the other has an orange band, they know that they can pull more water from the green band. This has effectively increased their fire fighting ability by this simple method. 
The hydrant bands are made of 3M Reflective Tape on aluminum bands. The material is made from the same material used in making "Stop" signs. The hydrant bands are easily discernable at night. This conforms to the objective of the City in that we would want to re-model and re-tag each fire hydrant in the City on a minimum of a 10 year cycle. This would account for any system changes.
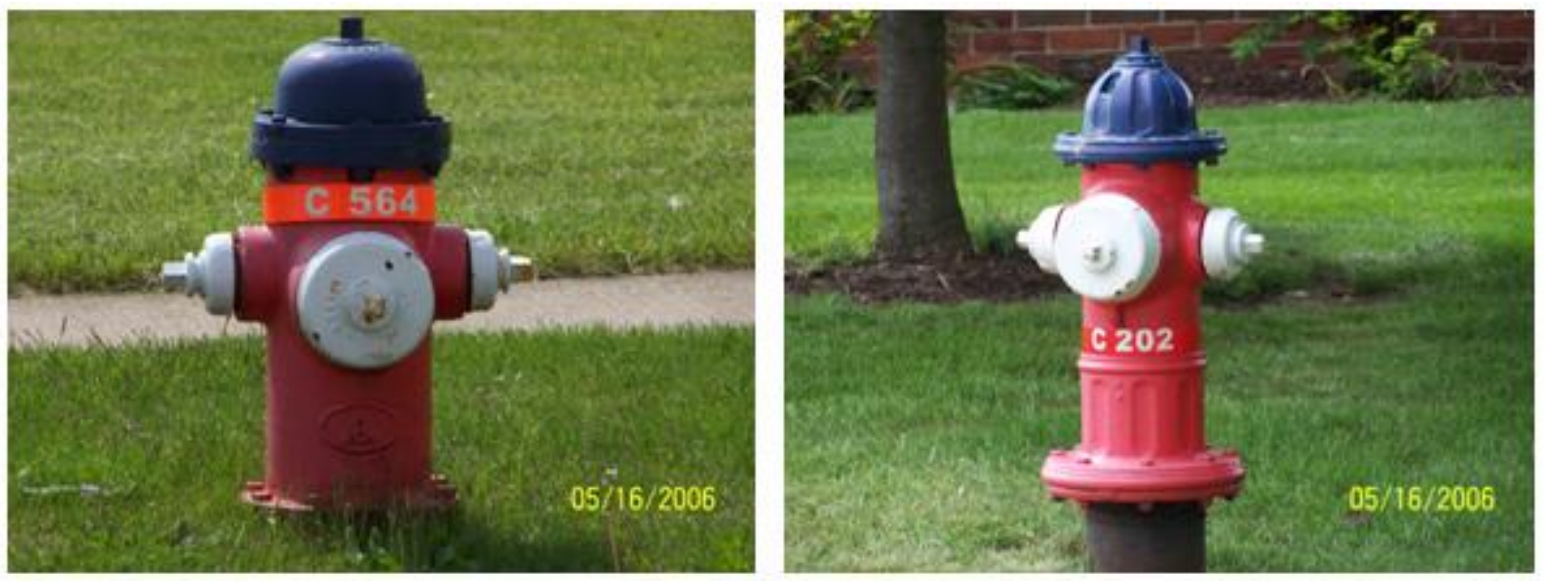

Figure 4 (c) Orange hydrant: 500 - 1,000 gpm (d) Red hydrant: < 500 gal/min

\section{CONCLUSIONS}

The modeling approach adopted by City of Sidney has proved the successful application of intelligent modeling technology that has been advanced over last decade. The integrated hydraulic simulation and genetic algorithm optimization approach designates a competent modeling framework and offers a powerful tool for constructing accurate water distribution model and enabling the informed system analysis. The GA-based calibration method facilitates a variety of practical network model calibration tasks including flow balance calibration and hydraulic grade calibration under static and fire flow conditions. Well established and calibrated model has been a valuable tool for the City to conduct many projects of system development, maintenance and operation management.

\section{REFERENCES}

Haestad Methods (2002) WaterCAD Software Manual, Haestad Mthods Inc., 37 Brookside Rd, Waterbury, CT06708, USA.

Bentley System, Incorporated (2006) WaterGEMS v8 Software Manual, Haestad Methods Solution Center, 27 Simon Co Dr, Suite200W, Watertown, CT 06795, USA.

Wu, Z. Y, Walski, T., Mankowski, R., Cook, J. Tryby, M. and Herrin G. (2002) "Calibrating Water Distribution Model Via Genetic Algorithms", in Proceedings of the AWWA IMTech Conference, April 16-19, Kansas City, MI.

Wu, Z. Y., Elio F. A. and Ernesto G. (2004) "Darwin Calibrator - Improving Project Productivity and Model Quality for Large Water Systems” J. of AWWA, Vol. 96, No.10, pp27-34. 